CNS Spectrums (2016), 21, 393-402. C Cambridge University Press 2016. The online version of this article is published within an Open Access environment subject to the conditions of the Creative Commons Attribution-NonCommercial-ShareAlike licence <http://creativecommons.org/licenses/by-nc-sa/3.0/>. The written permission of Cambridge University Press must be obtained for commercial re-use. doi:10.1017/S1092852915000917

\title{
Long-term safety and effectiveness of lurasidone in schizophrenia: a 22-month, open-label extension study
}

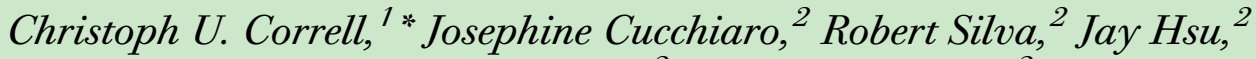 \\ Andrei Pikalov, ${ }^{2}$ and Antony Loebel ${ }^{2}$
}

${ }^{1}$ The Zucker Hillside Hospital, Psychiatry Research, North Shore-Long Island Jewish Health System, Glen Oaks Albert Einstein College of Medicine, Bronx, New York, USA

${ }^{2}$ Sunovion Pharmaceuticals Inc., Ft. Lee, New Jersey, USA

Objective. To evaluate the safety and effectiveness of lurasidone in the long-term treatment of patients with schizophrenia.

Methods. Patients who completed a 6-week, double-blind (DB), placebo-controlled trial continued in a 22-month, open-label (OL) study during which they received once-daily, flexible-doses of lurasidone, $40-120 \mathrm{mg}$. Change in the Positive and Negative Syndrome Scale (PANSS) was analyzed using both observed case (OC) and last observation carried forward (LOCF) analyses.

Results. Of the 251 patients who entered the OL extension, $51.4 \%$ completed 6 months, $36.7 \%$ completed 12 months, and $26.7 \%$ completed 22 months of OL treatment. Treatment with lurasidone was associated with a mean change from DB baseline, in weight of $+0.4 \mathrm{~kg}$ at Month $12(\mathrm{n}=99)$, and $+0.8 \mathrm{~kg}$ at Month $24(\mathrm{n}=67 ; \mathrm{OC}$ analyses $)$. Median change from DB baseline to Month 12 and Month 24, respectively, was -1.0 and $-9.0 \mathrm{mg} / \mathrm{dL}$ for total cholesterol; 0.0 and $-1.0 \mathrm{mg} / \mathrm{dL}$ for LDL; +1.0 and $-11.0 \mathrm{mg} / \mathrm{dL}$ for triglycerides; and 0.0 and $+0.1 / \%$ for HbA1c (OC analyses). The mean PANSS total score was 96.5 at DB baseline and 69.5 at OL baseline. The mean change from DB baseline in the PANSS total score at Month 24 was -43.6 (OC) and -28.4 (LOCF). Thirty-seven patients (14.7\%) discontinued due to an adverse event (AE) during OL treatment. Three AEs occurred in $\geq 10 \%$ of patients: schizophrenia (12.4\%), akathisia (10.8\%), and somnolence (10.8\%); and $19.2 \%$ reported at least one movement disorder-related AE. Discontinuations due to AEs occurred in $14.8 \%$ of patients.

Conclusions. In this 22-month, open-label extension study, treatment with lurasidone was associated with minimal effects on weight, glucose, lipids, and prolactin. Patients demonstrated sustained improvement in the PANSS total score for up to 24 months of lurasidone treatment.

Received 24 June 2015; Accepted 2 October 2015; First published online 6 April 2016

Key words: Atypical antipsychotic, lurasidone, maintenance treatment, safety, schizophrenia.

\footnotetext{
* Address for correspondence: Christoph U. Correll, MD, North Shore Long Island Jewish Health System, The Zucker Hillside Hospital, Psychiatry Research, 75-59 263rd Street, Glen Oaks, NY 11004, USA.

(Email: ccorrell@lij.edu)

This study was sponsored by Sunovion Pharmaceuticals Inc. ClinicalTrials.gov Identifier: NCT00549718.

The authors would like to thank the patients who participated in this study, as well as the study investigators: Mocrane Abbar, Khairudin Abd. Wahab, Volodymyr Abramov, Padmini Atri, Vinay Barhale, Valeriy Bitenskyy, Yuliya Blazhevych, James Booker, Mikhail Burdukovsky, Mark Burkin, Miranda Chakos, Andrew Cutler, Svetlana Danilova, Steven Dubovsky, Carlos Figueroa, David Flaherty, Lorentina Florescu, Hitendra A.Gandhi, Donald Garcia, Elena Gherman, Venu Gopal Jhanwar, Gregory Kaczenski, Alexandr Kolchev, Alexander Kotsubinsky, Mark Lerman, Robert Litman, Adam Lowy, Raymond Manning, Morteza Marandi, Gabriel Marinescu, Svitlana Moroz, Mark Novitsky, Pavel Palamarchuk, Michael Plopper, Delia Podea, Mikhail Popov, N. N.Raju, Robert Riesenberg, Murray Rosenthal, Maria Sandulescu, Ramanathan Sathianathan, Kenneth Sokolski, Thatikonda Padma Sudhakar, Ahmad Hatim Sulaiman, Vladimir Tochilov, Anita Varma, Iryna Vlokh, David Walling, Kashinath Yadalam, and Marie-Agathe Zimmermann. Edward Schweizer, MD, provided editorial assistance in the preparation of an early draft of the manuscript that was funded by Sunovion Pharmaceuticals Inc.
} 


\section{Introduction}

Long-term safety is an important consideration when choosing an antipsychotic agent for maintenance treatment of schizophrenia. This is especially relevant for benefit-risk assessments, since differences in efficacy among available antipsychotic agents appear to be smaller than differences in safety, ${ }^{1-3}$ with differential effects on weight and metabolic parameters, as well as related cardiovascular morbidity, causing the greatest concern. ${ }^{4-7}$

Lurasidone hydrochloride (HCl), a benzisothiazol derivative, is a second-generation antipsychotic agent with potent binding affinity for $\mathrm{D}_{2}, 5-\mathrm{HT}_{2 \mathrm{~A}}$, and $5 \mathrm{HT}_{7}$ receptors (antagonist effect); nanomolar affinity for $5 \mathrm{HT}_{1 \mathrm{~A}}$ receptors (partial agonist effect); moderate affinity to $\alpha_{2 \mathrm{C}}$ receptors (antagonist effect); weak affinity (>400 nM) for $5-\mathrm{HT}_{2 \mathrm{C}}$ receptors; and little or no affinity for $\mathrm{H}_{1}$ and $\mathrm{M}_{1}$ receptors. ${ }^{8}$

The efficacy of lurasidone in the short-term treatment of acute exacerbations of schizophrenia has been demonstrated in a series of double-blind, placebocontrolled short-term studies. ${ }^{9-13}$ Based, in part, on these data, lurasidone received marketing authorization for the treatment of adults with schizophrenia from the Food and Drug Administration in 2010, and from the European Medicines Agency in 2014, as well as from the regulatory authorities in Switzerland, Canada, and Australia. Additionally, lurasidone has received U.S. and Canadian regulatory approval for the treatment of adults with major depressive episodes associated with bipolar I disorder, as either a monotherapy or as adjunctive therapy with lithium or valproate. ${ }^{14,15}$ In short-term, placebo-controlled trials, lurasidone appeared to be associated with particularly low weight gain and metabolic risk potential across these indications compared to what has been reported for several other second-generation antipsychotics (eg, olanzapine, risperidone, quetiapine). ${ }^{16}$

Previous longer-term continuation studies suggest that the efficacy of lurasidone is maintained over 6-12 months with a low potential for adverse effects on weight and metabolic parameters, making it a promising candidate for maintenance treatment. ${ }^{17-19}$ The efficacy of lurasidone in maintaining initial response has been confirmed in a double-blind relapse prevention study in which 12 months of treatment with lurasidone $(40-160 \mathrm{mg} /$ day $)$ was associated with a significantly lower risk of relapse compared with quetiapine XR (200-800 mg/day), with a hazard ratio of 0.728 , indicating a $27.2 \%$ reduction in relapse risk. Treatment with lurasidone was also associated with significantly higher remission rates compared to quetiapine XR (62\% vs. $46 \%$; $p<0.05$; based on Remission in Schizophrenia Working Group criteria). ${ }^{19,20}$

We report here the results of an open-label study in which patients diagnosed with an acute exacerbation of schizophrenia who completed an initial 6-week, double-blind, placebo-controlled, fixed-dose trial (lurasidone $40 \mathrm{mg} / \mathrm{d}, 80 \mathrm{mg} / \mathrm{d}, 120 \mathrm{mg} / \mathrm{d}$ ) received 22 months of additional treatment with flexible-doses of lurasidone, $40-120 \mathrm{mg} /$ day. The aim of the current study was to evaluate the safety, tolerability, and effectiveness of lurasidone in the long-term treatment of patients with a Diagnostic and Statistical Manual of Mental Disorders, Fourth Edition, Text Revision (DSM-IV-TR) diagnosis of schizophrenia.

\section{Methods}

The current open-label study is the continuation of an initial acute study ${ }^{21}$ in which patients, ages 18-75 years inclusive, who met DSM-IV-TR criteria for an acute exacerbation of schizophrenia, and were currently hospitalized, were randomized to 6 weeks of doubleblind treatment with once-daily fixed doses of either lurasidone (40 mg, $80 \mathrm{mg}, 120 \mathrm{mg}$ ) or placebo.

Patients who completed acute, double-blind treatment with either lurasidone or placebo were continued in the current 22-month, open-label extension study. Double-blind study medication was discontinued, and patients were started, open-label, on an $80 \mathrm{mg} /$ day dose of lurasidone. After 7 days of treatment, the dose could be adjusted in $40 \mathrm{mg}$ increments, on a weekly basis, within the flexible dosing range of $40-120 \mathrm{mg} / \mathrm{d}$, as deemed necessary by study investigators. A maximum of 4 dose adjustments were permitted during the 22 months of open-label treatment period. Medication was taken once daily in the morning with a meal or within 30 minutes after eating.

Prior to beginning this open label extension study, an informed consent document explaining study procedures and potential risks was reviewed and signed by all patients. The study protocol, and all related forms and amendments, were approved by an Independent Ethics Committee associated with each study center. The study was conducted in 48 study centers in France $(n=1)$, India $(\mathrm{n}=6)$, Malaysia $(\mathrm{n}=2)$, Romania $(\mathrm{n}=5)$, Russia $(\mathrm{n}=7)$, Ukraine $(\mathrm{n}=6)$, and the United States $(\mathrm{n}=21)$ in accordance with Good Clinical Practices as required by the International Conference on Harmonisation guidelines and in accordance with ethical principles of the Declaration of Helsinki. An independent Data and Safety Monitoring Board reviewed safety and clinical outcome data at regular intervals during the study.

\section{Assessments}

On-treatment assessment visits during the open-label extension phase occurred at monthly intervals up through Month 24, with the exception of a Week 8 visit that occurred 2 weeks after completion of the 6-week 
double-blind initial study. To evaluate the long-term safety and tolerability of lurasidone, adverse events (AEs) and vital signs were recorded. Extrapyramidal symptoms were assessed with the Simpson-Angus Scale (SAS), ${ }^{22}$ Barnes Akathisia Rating Scale (BARS), ${ }^{23}$ and Abnormal Involuntary Movements Scale (AIMS) ${ }^{24}$ at Week 8, Months 3-6, and Months 9, 12, 15, 18, 21, and 24 (or early termination). Samples for fasting laboratory tests (chemistry and hematology panels, lipid panel, glycosylated hemoglobin [HbA1c], prolactin) were obtained at Week 8, Month 3, and every 3 months thereafter. Physical examination was performed at Months 6, 12, 18, and 24 (or early termination). Electrocardiogram (ECG) was recorded at Week 8, and Months 6, 12, 18, and 24 (or early termination). The Fridericia formula was used for calculation of heart rate-adjusted QT interval (QTc).

Efficacy was assessed using the Positive and Negative Syndrome Scale (PANSS), ${ }^{25}$ the Clinical Global ImpressionSeverity Scale (CGI-S), ${ }^{24}$ and the Montgomery-Åsberg Depression Rating Scale (MADRS). ${ }^{26}$ PANSS, CGI-S, and MADRS evaluations were performed at regular intervals.

\section{Statistical methods}

The primary objective of this open-label extension phase study was to evaluate the safety and tolerability of lurasidone in patients with schizophrenia. Categorical parameters, for baseline and on-treatment parameters, were summarized by presenting the number (n) and percentage of patients in each category. Continuous parameters were summarized using $n$, mean, and/or median values. Variability was expressed in terms of standard deviation (SD) or 95\% confidence intervals (CIs), which were 2-sided, unless otherwise specified. Number needed to treat (NNT) and within-group effect sizes were calculated. For patients who discontinued prematurely, the last post-baseline measurement was utilized, and was defined as the last observation carried forward (LOCF) for that phase; observed case (OC) analyses were also performed. Criteria for abnormal laboratory and ECG values were specified a priori based on standard values.

In a post-hoc analysis, patients who had an improvement of at least $20 \%$ from the acute phase baseline in PANSS total score were defined as responders, while remission was defined using the Remission in Schizophrenia Working Group (RSWG) criteria for symptomatic remission, which requires that a score $\leq 3$ (mild or better) be maintained for at least 6 months on all of the following 8 PANSS items: G5, G9, N1, N4, N6, P1, P2, P3. ${ }^{20}$ A Kaplan-Meier estimate of time-to-remission probabilities was calculated for the 2 groups of patients entering the current open-label extension study: acute phase responders and non-responders; differences between the 2 groups were analyzed using the logrank test. Patients who met remission criteria at open-label baseline were not included in the remission analyses. All statistical analyses were performed using SAS software Version 8.2 (SAS Institute, Inc., Cary, NC, USA).

\section{Findings}

A total of 496 patients were randomized in the core acute study, of whom $328(66.1 \%)$ completed 6 weeks of double-blind treatment with one of 3 doses of lurasidone, or placebo. Of those completers, 251 (76.5\%) elected and were eligible to continue in the current open-label extension study, 62 from the lurasidone $40 \mathrm{mg}$ group, 65 from the lurasidone $80 \mathrm{mg}$ group, 65 from the lurasidone $120 \mathrm{mg}$ group, and 59 from the placebo group (Figure 1). This comprised the population used for both safety and efficacy analyses (1 patient did not

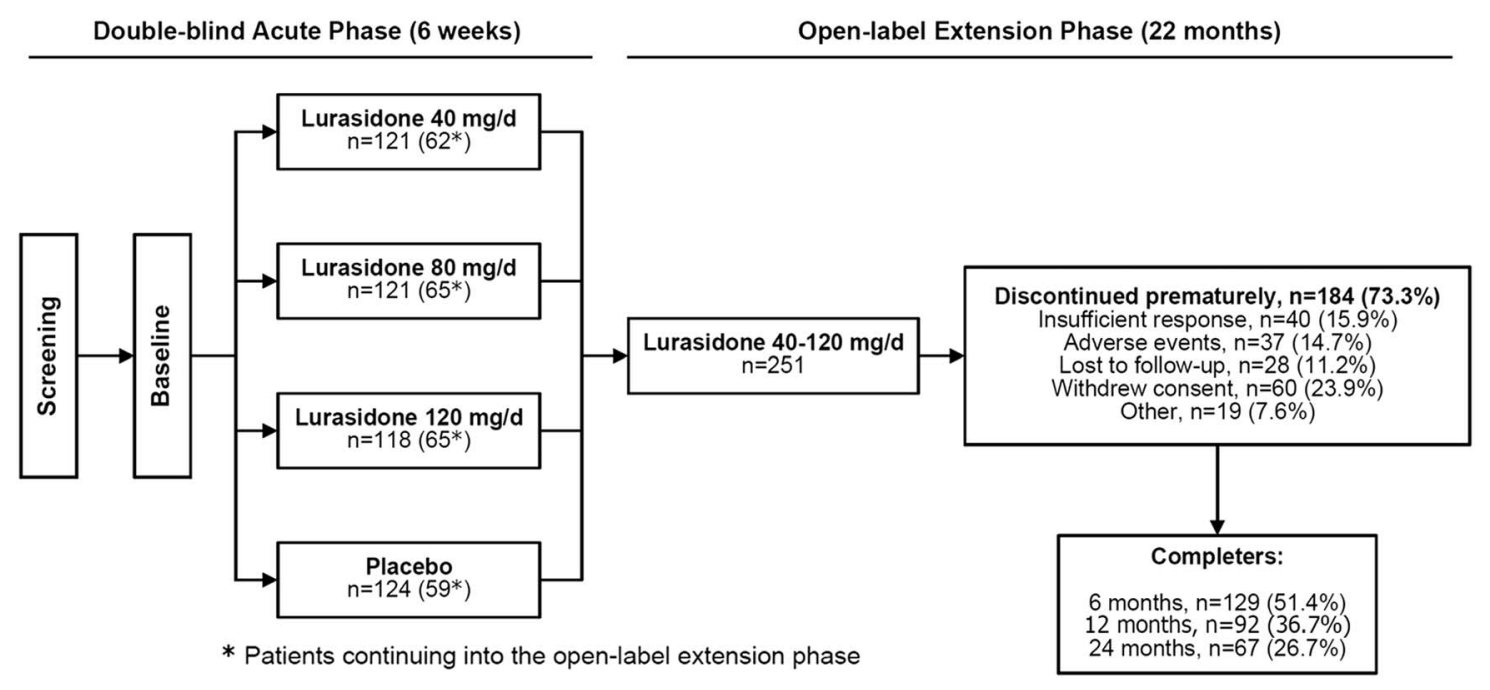

FIGURE 1. Study flow diagram and patient disposition during acute double-blind ( 6 weeks) and open-label (22 months) treatment with lurasidone. 
receive a dose of lurasidone and was excluded from the analyses). A total of $36.7 \%$ of patients completed 12 months of open-label extension phase treatment, and $26.7 \%$ completed the full 22 months of extension treatment. Withdrawal of consent was the most common reason for discontinuation, followed by insufficient clinical response, discontinuation due to an adverse event, lost to follow-up, protocol violation, and miscellaneous other reasons (Figure 1).

Baseline demographic and clinical characteristics of the safety population are summarized in Table 1 . Patients who were switched from placebo to lurasidone (versus patients who continued on lurasidone) were more likely to be male ( $73 \%$ vs $62 \%$ ) and were more likely to have had 4 or more hospitalizations (64\% vs $56 \%$; Table 1); other baseline variables were approximately similar for each group.

The mean (SD) daily dose of lurasidone for all patients was 87.8 (19.8) $\mathrm{mg}$. The proportion of patients using modal daily doses of $40 \mathrm{mg}, 80 \mathrm{mg}$, and $120 \mathrm{mg}$, respectively, was similar at 6 months $(13 \%, 42 \%, 45 \%)$, 1 year $(15 \%, 38 \%, 47 \%)$, and 2 years $(16 \%, 39 \%, 45 \%)$. Of the 191 patients for whom compliance data were available, all but 1 met a priori compliance criteria throughout the study of (pill counts within a range of $75 \%$ to $125 \%$ of prescribed dosing).

\section{Safety \\ Adverse events}

Approximately two-thirds of patients reported one or more treatment-emergent adverse events (AEs) during 22-month open-label treatment (Table 2). The most frequently reported AEs were schizophrenia, akathisia, and somnolence (Table 2). Overall, 9.2\% of patients reported an $\mathrm{AE}$ rated as severe; the incidence of a rating as severe was $<2 \%$ for all individual events.

In general, initial double-blind treatment assignment did not appear to influence the frequency of AEs during open-label treatment, with the exception of 3 AEs that were reported with a higher frequency in the subgroup switched from placebo (in the double-blind phase) to lurasidone when compared to patients continuing on lurasidone, respectively: nausea (18.6\% vs. $5.2 \%)$, vomiting ( $16.9 \%$ vs. $6.3 \%)$, and anxiety ( $16.9 \%$ vs. $4.7 \%)$.

A total of 49 patients (19.6\%) reported one or more AEs categorized as "serious" during 24 months of open-label treatment. The only serious AEs reported by $\geq 1 \%$ of

\section{TABLE 1 . Baseline characteristics (safety population)}

\begin{tabular}{|c|c|c|c|c|}
\hline & \multicolumn{2}{|c|}{ Lurasidone (acute) and lurasidone (extension) $(\mathrm{N}=191$ ) } & \multicolumn{2}{|c|}{ Placebo (acute) and lurasidone (extension) $(\mathrm{N}=59)$} \\
\hline & $n$ & $\%$ & $\mathrm{n}$ & $\%$ \\
\hline Male & 119 & 62 & 43 & 73 \\
\hline \multicolumn{5}{|l|}{ Race } \\
\hline White & 95 & 50 & 34 & 58 \\
\hline Black/African American & 56 & 29 & 15 & 25 \\
\hline Asian & 38 & 20 & 9 & 15 \\
\hline Other & 2 & 1 & 1 & 2 \\
\hline Ethnicity, Hispanic/Latino & 7 & 4 & 3 & 5 \\
\hline \multirow[t]{2}{*}{ Prior hospitalizations: $\geq 4$} & 107 & 56 & 38 & 64 \\
\hline & Mean & SD & Mean & SD \\
\hline Age, years & 38.3 & 10.7 & 38.8 & 10.0 \\
\hline Age at onset of illness, years & 25.1 & 8.6 & 24.2 & 8.5 \\
\hline Duration of illness, years & 12.7 & 9.7 & 14.2 & 10.4 \\
\hline Duration of current episode, days & 32.4 & 12.3 & 32.8 & 14.4 \\
\hline \multicolumn{5}{|l|}{ PANSS total score } \\
\hline Double-blind baseline & 96.8 & 10.4 & 95.5 & 10.1 \\
\hline Open-label baseline & 69.8 & 16.2 & 68.4 & 17.4 \\
\hline \multicolumn{5}{|l|}{ CGI-S score } \\
\hline Double-blind baseline & 4.9 & 0.6 & 4.9 & 0.5 \\
\hline Open-label baseline & 3.4 & 0.8 & 3.5 & 0.9 \\
\hline \multicolumn{5}{|l|}{ MADRS total score } \\
\hline Double-blind baseline & 10.6 & 6.7 & 11.4 & 6.0 \\
\hline Open-label baseline & 6.1 & 5.3 & 6.2 & 5.0 \\
\hline
\end{tabular}

Lurasidone (acute) and (extension): Treated with lurasidone during double-blind acute study, then continued on lurasidone during open-label extension study. Placebo (acute) and lurasidone (extension): Treated with placebo during double-blind acute study, then switched to lurasidone during open-label extension study.

PANSS: Positive and Negative Symptom Scale; CGI-S: Clinical Global Impression scale-Severity; MADRS: Montgomery-Åsberg Depression Rating Scale; SD: standard deviation. 
TABLE 2 . Incidence of adverse events reported by $\geq 5 \%$ of patients during 22 -month open-label study

\begin{tabular}{|c|c|c|c|c|}
\hline & \multicolumn{2}{|c|}{ Total lurasidone $(\mathrm{N}=250)$} & \multicolumn{2}{|c|}{ Lurasidone (acute) and lurasidone (extension) $(\mathrm{N}=191$ ) } \\
\hline & N & $\%$ & N & $\%$ \\
\hline At least one AE & 172 & 68.8 & 125 & 65.4 \\
\hline Schizophrenia & 31 & 12.4 & 23 & 12.0 \\
\hline Akathisia & 27 & 10.8 & 22 & 11.5 \\
\hline Somnolence & 27 & 10.8 & 20 & 10.5 \\
\hline Vomiting & 22 & 8.8 & 12 & 6.3 \\
\hline Nausea & 21 & 8.4 & 10 & 5.2 \\
\hline Insomnia & 20 & 8.0 & 16 & 8.4 \\
\hline Anxiety & 19 & 7.6 & 9 & 4.7 \\
\hline Parkinsonism & 16 & 6.4 & 14 & 7.3 \\
\hline Headache & 15 & 6.0 & 12 & 6.3 \\
\hline Weight decreased & 15 & 6.0 & 10 & 5.2 \\
\hline At least 1 EPS-related event* & 48 & 19.2 & 39 & 20.4 \\
\hline
\end{tabular}

patients were schizophrenia $(10.0 \%)$ and psychotic disorder (2.8\%). One suicide attempt (overdose of antihistamine, doxylamine, taken for insomnia) occurred. The event was judged by the investigator to be "unlikely related" to study drug; the patient recovered. A second suicide attempt (ingestion of a large amount of alcohol) was judged to be non-serious, "unrelated" to study drug, and did not result in hospitalization. There were 2 deaths during the open-label extension phase: 1 due to traumatic brain injury suffered in a car accident and 1 due to burns from a kitchen fire. Both were considered unrelated to study medication. Five patients experienced serious AEs that were judged to be related or probably related to lurasidone: relapse/exacerbation of schizophrenia ( $\mathrm{n}=3$ patients), akathisia $(\mathrm{n}=2)$, Parkinsonism $(\mathrm{n}=1)$.

\section{Physical examination and vital signs}

There were no clinically significant treatment-emergent changes during open-label treatment with lurasidone in pulse rate, systolic or diastolic blood pressure, or body temperature.

\section{Extrapyramidal symptoms}

The proportion of patients reporting the EPS-related adverse events of Parkinsonism (6.4\%) and akathisia (10.8\%) is summarized in Table 2. There was a low incidence of other EPS-related symptoms such as tremor $(2.4 \%)$ and dystonia (1.6\%). Four patients (1.6\%) discontinued study medication due to akathisia and 1 $(0.4 \%)$ due to tardive dyskinesia. The majority of patients remained unchanged from open-label baseline to LOCFendpoint in their scores on the AIMS (91.5\%), the BARS Global Clinical Assessment of Akathisia (80.0\%), and the
SAS (83.4\%). Among patients reporting a change, a similar proportion reported categorical worsening compared to improvement on the AIMS (4.3\% vs $4.3 \%$, respectively) and the BARS Global Clinical Assessment of Akathisia (10.2\% vs $9.8 \%$, respectively); while a higher proportion reported categorical worsening compared to improvement on the SAS ( $14.5 \%$ vs $2.1 \%$, respectively). Overall, 54 patients $(21.6 \%)$ were treated with an anticholinergic medication; other classes of concomitant medication used by at least $10 \%$ of patients consisted of anxiolytics $(36.8 \%)$, sedative-hypnotics $(22.4 \%)$, and nonsteroidal anti-inflammatory drugs (11.2\%).

Body weight, body mass index (BMI), and waist circumference

A small increase in mean weight was observed during lurasidone treatment at Months 12 and 24 in both the total sample and in the lurasidone continuation group (Table 3; OC analysis). At Month 12, clinically significant $(\geq 7 \%$ change) weight gain occurred in $14.1 \%$ of patients $(n=99)$ in the total sample (observed case analysis), and clinically significant weight loss occurred in 12.1\%; at Month 24, clinically significant weight gain occurred in $22.4 \%$ of patients $(n=67)$, and clinically significant weight loss occurred in $11.9 \%$. No clinically significant mean increases were observed in either BMI or waist circumference at Months 12 or 24 (Table 3; OC analysis). For the total sample, a shift in BMI from underweight/normal to overweight occurred in $6.4 \%$ of patients (no patients became obese), while $4.7 \%$ shifted from overweight/obese to normal weight (LOCF-endpoint analysis).

\section{Metabolic parameters}

Overall, there were no clinically meaningful median changes from double-blind baseline in fasting lipid 
TABLE 3. Change in safety parameters from double-blind baseline to Month 12 and Month 24: observed case analysis

\begin{tabular}{|c|c|c|c|c|c|c|}
\hline & \multicolumn{3}{|c|}{ Total lurasidone } & \multicolumn{3}{|c|}{ Lurasidone (acute) and lurasidone (extension) } \\
\hline & $\mathrm{N}$ & Mean (SD) & Median change & $\mathrm{N}$ & Mean (SD) & Median change \\
\hline \multicolumn{7}{|l|}{ Weight (kg) } \\
\hline Double-blind baseline & 99 & $76.5(20.4)$ & & 77 & $75.2(19.9)$ & \\
\hline Month 12 change & 99 & $+0.4(6.3)$ & +0.8 & 77 & $+0.7(5.0)$ & +0.9 \\
\hline Month 24 change & 67 & $+0.7(8.0)$ & +0.9 & 51 & $+1.4(5.9)$ & +0.9 \\
\hline \multicolumn{7}{|l|}{ BMI $\left(\mathrm{kg} / \mathrm{m}^{2}\right)$} \\
\hline Double-blind baseline & 99 & $26.4(5.7)$ & & 77 & $26.0(5.6)$ & \\
\hline Month 12 change & 99 & $+0.2(2.3)$ & +0.3 & 77 & $+0.3(1.9)$ & +0.3 \\
\hline Month 24 change & 67 & $+0.3(2.9)$ & +0.3 & 51 & $+0.5(2.3)$ & +0.3 \\
\hline \multicolumn{7}{|l|}{ Waist circumference (cm) } \\
\hline Double-blind baseline & 99 & $89.4(15.7)$ & & 77 & $89.2(16.0)$ & \\
\hline Month 12 change & 99 & $+0.4(5.5)$ & +0.1 & 77 & $+0.3(4.6)$ & +0.1 \\
\hline Month 24 change & 67 & $+0.6(5.7)$ & +1.0 & 51 & $+0.6(4.7)$ & +1.0 \\
\hline \multicolumn{7}{|l|}{ Total cholesterol (mg/dL) } \\
\hline Double-blind baseline & 99 & $185.9(39.9)$ & & 77 & $183.7(38.4)$ & \\
\hline Month 12 change & 99 & $+0.1(30.6)$ & -1.0 & 77 & $-0.8(29.5)$ & 0.0 \\
\hline Month 24 change & 64 & $-3.8(32.4)$ & -9.0 & 48 & $-4.6(28.5)$ & -12.0 \\
\hline \multicolumn{7}{|l|}{ LDL cholesterol (mg/dL) } \\
\hline Double-blind baseline & 99 & $109.6(29.4)$ & & 77 & $109.8(27.9)$ & \\
\hline Month 12 change & 99 & $+1.4(23.2)$ & 0.0 & 77 & $+1.9(22.9)$ & 0.0 \\
\hline Month 24 change & 64 & $-2.7(22.5)$ & -1.0 & 48 & $-2.8(21.5)$ & -2.5 \\
\hline \multicolumn{7}{|l|}{ HDL cholesterol (mg/dL) } \\
\hline Double-blind baseline & 99 & $44.4(13.3)$ & & 77 & $44.8(13.8)$ & \\
\hline Month 12 change & 99 & $-2.1(9.9)$ & -1.0 & 77 & $-2.2(10.0)$ & -1.0 \\
\hline Month 24 change & 64 & $-2.4(10.6)$ & -2.0 & 48 & $-2.4(10.8)$ & 0.0 \\
\hline \multicolumn{7}{|l|}{ Triglycerides (mg/dL) } \\
\hline Double-blind baseline & 99 & $156.2(104.8)$ & & 77 & $145.4(101.5)$ & \\
\hline Month 12 change & 99 & $+1.3(118.1)$ & +1.0 & 77 & $-7.9(87.7)$ & +1.0 \\
\hline Month 24 change & 64 & $-2.0(126.5)$ & -11.0 & 48 & $-15.1(117.1)$ & -13.0 \\
\hline \multicolumn{7}{|l|}{ Glucose (mg/dL) } \\
\hline Double-blind baseline & 98 & $93.6(12.3)$ & & 76 & $93.4(12.2)$ & \\
\hline Month 12 change & 98 & $+4.0(18.7)$ & +4.0 & 76 & $+5.0(19.2)$ & +4.0 \\
\hline Month 24 change & 65 & $+1.6(18.4)$ & +2.0 & 49 & +3.3 (17.3) & +4.0 \\
\hline \multicolumn{7}{|l|}{ HbA1c (\%) } \\
\hline Double-blind baseline & 96 & $5.57(0.4)$ & & 74 & $5.59(0.4)$ & \\
\hline Month 12 change & 96 & $-0.04(0.4)$ & 0.00 & 74 & $-0.02(0.3)$ & 0.00 \\
\hline Month 24 change & 61 & $+0.13(0.4)$ & +0.10 & 46 & $+0.16(0.31)$ & +0.10 \\
\hline \multicolumn{7}{|l|}{ Prolactin (ng/mL) } \\
\hline Double-blind baseline & 98 & $14.3(17.0)$ & & 76 & $14.4(17.1)$ & \\
\hline Month 12 change & 98 & $+1.3(24.6)$ & -1.3 & 76 & $-1.4(18.8)$ & -1.8 \\
\hline Month 24 change & 66 & $-2.3(19.0)$ & -1.0 & 50 & $-2.3(17.3)$ & -1.0 \\
\hline
\end{tabular}

parameters (total cholesterol, triglycerides, LDL or HDL cholesterol) or measures of (non-fasting) glycemic control (glucose, HbA1c) during 24 months of treatment with lurasidone (Table 3). From double-blind baseline to Month 24, a smaller proportion of patients had a categorical shift from normal-to-high values compared to high-to-normal values for total cholesterol (6.8\% vs. $16.0 \%)$, LDL cholesterol (9.6\% vs. 6.8\%), and for triglycerides (8.2\% vs. 9.1\%; Figure 2). A higher proportion of patients had a categorical shift from normal-to-high values compared to high-to-normal values for $\mathrm{HbA1c}(6.1 \%$ vs. $4.7 \%$; Figure 2).
Prolactin and other laboratory values

For the total sample, there were minimal changes from double-blind baseline in mean and median prolactin levels at Months 12 and 24 (Table 3). Median reductions in prolactin from double-blind baseline were somewhat greater for males versus females at Month 12 (-1.7 vs. $-0.1 \mathrm{ng} / \mathrm{mL}$ ) and Month 24 (-1.6 vs. $-0.6 \mathrm{ng} / \mathrm{mL})$. When change was calculated from open-label baseline for the total sample, small reductions occurred in mean and median prolactin levels at Months 12 and 24; median reductions in prolactin were greater for males versus 
females at both assessment time-points. A treatmentemergent shift from normal (at double-blind baseline) to high (abnormal) prolactin levels occurred in 10 males $(7.2 \%$; criterion for high value $>17.7 \mathrm{ng} / \mathrm{mL})$ and 10 females (12.5\%; criterion for high value $>29.2 \mathrm{ng} / \mathrm{mL}$ ). No patients in any treatment group discontinued study medication due to elevated prolactin.

There was no evidence for hepatic toxicity during 24 months of treatment with lurasidone. There were minor, clinically insignificant changes from open-label baseline to LOCF-endpoint in ALT and AST. Four patients $(1.7 \%)$ had a markedly abnormal ALT and 3 patients (1.3\%) had a markedly abnormal AST during open-label treatment; the abnormalities resolved in all but 1 subject, and none resulted in discontinuation from the study medication. There were no other clinically meaningful changes in mean chemistry or hematology lab values during the course of the study.

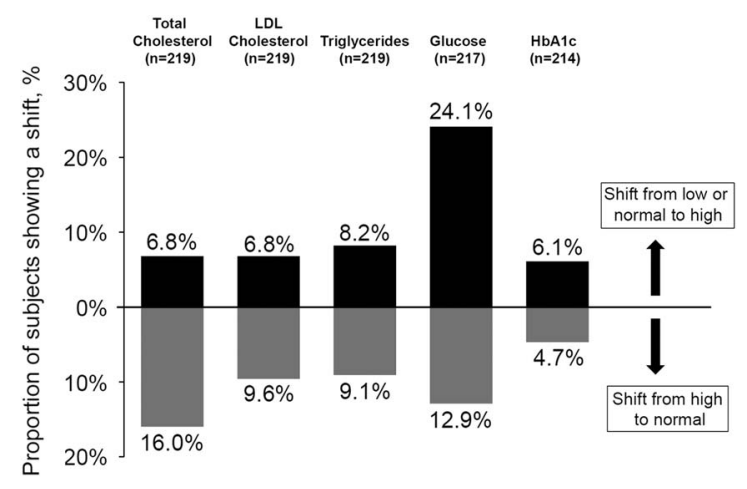

FIGURE 2. Proportion of patients treated with lurasidone whose laboratory values showed a double-blind baseline to endpoint shift between low/normal and high. Criteria for shift to high values were as follows: total cholesterol ( $>200 \mathrm{ng} / \mathrm{mL}$ ), triglycerides (>203 ng/mL), glucose ( $\geq 100 \mathrm{mg} / \mathrm{dL}$ ), HbAlc $(>6 \%)$. Glucose measurements were fasting, based on patient report; no additional measures were taken to confirm fasting status.

\section{ECG}

There were no clinically meaningful changes in mean ECG parameters during open-label treatment with lurasidone. The mean (SD) change from baseline in QTcF was 4.7 (17.8) msec (LOCF-endpoint). No patients had a QTcF interval of $>500 \mathrm{msec}$ at any time from double-blind baseline to Month 24. For this overall treatment period, 2 patients $(0.9 \%)$ had $\geq 60 \mathrm{msec}$ increase in QTcF interval.

\section{Efficacy}

Among patients who entered the current extension phase study, the initial 6 weeks of double-blind treatment was associated with comparable levels of improvement in mean PANSS total score in the group randomized to lurasidone (-27.0) and the group randomized to placebo (-27.1). For the combined treatment groups, the mean PANSS total score decreased from 96.5 to 69.5 . Over the course of 24 months, treatment with lurasidone was associated with continued improvement beyond what was achieved in the PANSS total and subscale scores after the initial 6 weeks of double-blind treatment (Figure 3; OC analysis). Continued improvement was observed, both in patients initially randomized, in the acute phase, to lurasidone, and to placebo (Table 4). Improvement slightly favored patients treated with lurasidone during the initial double-blind phase.

For month 6 and month 12 completers (OC analysis), the proportion of patients who met full RSWG criteria for remission was $62 \%$ at 6 months and $67 \%$ at 12 months. When dropouts were included (LOCF-analysis), the proportion of patients who met full RSWG criteria for remission was $33 \%$ at 6 months and $28 \%$ at 12 months. Remission was not assessed beyond 12 months due to small sample sizes. A Kaplan-Meier analysis showed a higher probability of achieving

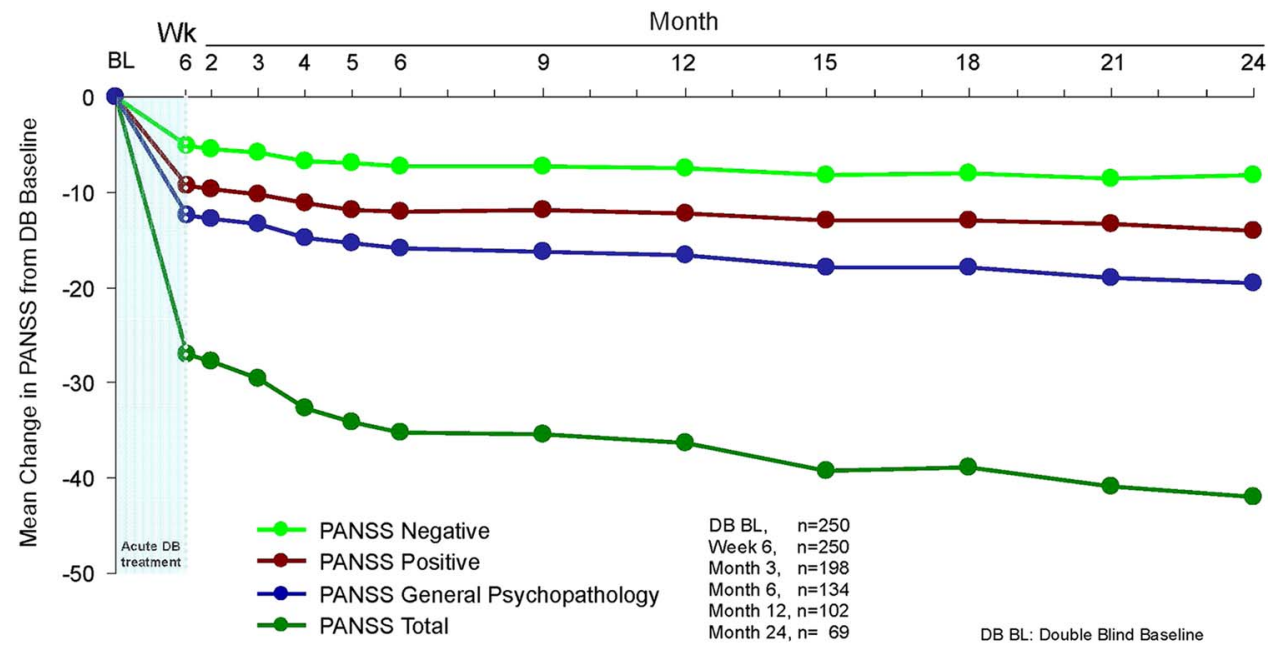

FIGURE 3. Change from double-blind baseline in PANSS total and subscale scores during 24 months of lurasidone treatment (OC analysis). 
TABLE 4. Mean change in efficacy measures at month 24: observed case and LOCF-endpoint analysis

\begin{tabular}{|c|c|c|c|c|c|c|c|c|}
\hline & \multicolumn{4}{|c|}{ Lurasidone (acute) and Lurasidone (extension) } & \multicolumn{4}{|c|}{ Placebo (acute) and Lurasidone (extension) } \\
\hline & \multicolumn{2}{|c|}{ Observed $(n=52)$} & \multicolumn{2}{|c|}{ LOCF-endpoint $(n=179)$} & \multicolumn{2}{|c|}{ Observed $(n=17)$} & \multicolumn{2}{|c|}{ LOCF-endpoint $(n=56)$} \\
\hline & Mean (SD) & $95 \%-\mathrm{Cl}$ & Mean (SD) & $95 \%-\mathrm{Cl}$ & Mean (SD) & $95 \%-\mathrm{Cl}$ & Mean (SD) & $95 \%-\mathrm{Cl}$ \\
\hline \multicolumn{9}{|l|}{ PANSS total score } \\
\hline Change from DB baseline & $-43.6(15.9)$ & $-48.0,-39.1$ & $-28.4(20.5)$ & $-31.5,-25.4$ & $-36.8(14.5)$ & $-44.3,-29.4$ & $-26.4(18.6)$ & $-31.4,-21.5$ \\
\hline Change from $\mathrm{OL}$ baseline & $-13.1(16.9)$ & $-17.8,-8.4$ & $-0.9(20.0)$ & $-3.9,+2.0$ & $-9.7(13.8)$ & $-16.8,-2.6$ & $+0.7(19.3)$ & $-4.4,+5.9$ \\
\hline \multicolumn{9}{|l|}{ PANSS positive subscore } \\
\hline Change from DB baseline & $-14.6(5.0)$ & $-16.0,-13.2$ & $-9.8(7.6)$ & $-10.9,-8.7$ & $-12.1(4.3)$ & $-14.3,-9.9$ & $-8.4(6.3)$ & $-10.1,-6.7$ \\
\hline Change from OL baseline & $-3.8(4.4)$ & $-5.0,-2.6$ & $-0.1(6.4)$ & $-1.1,+0.8$ & $-3.4(4.3)$ & $-5.6,-1.1$ & $-0.0(6.0)$ & $-1.6,+1.6$ \\
\hline \multicolumn{9}{|l|}{ PANSS negative subscore } \\
\hline Change from DB baseline & $-8.4(5.5)$ & $-10.0,-6.9$ & $-5.9(5.5)$ & $-6.7,-5.1$ & $-8.0(4.5)$ & $-10.3,-5.7$ & $-6.0(5.0)$ & $-7.3,-4.6$ \\
\hline Change from $\mathrm{OL}$ baseline & $-3.0(5.1)$ & $-4.4,-1.6$ & $-0.6(5.4)$ & $-1.4,+0.2$ & $-2.6(4.5)$ & $-5.0,-0.3$ & $-0.5(4.4)$ & $-1.7,+0.7$ \\
\hline \multicolumn{9}{|l|}{ CGI-Sscore } \\
\hline Change from DB baseline & $-2.3(0.8)$ & $-2.5,-2.1$ & $-1.5(1.2)$ & $-1.7,-1.3$ & $-2.0(0.8)$ & $-2.4,-1.6$ & $-1.5(1.0)$ & $-1.7,-1.2$ \\
\hline Change from OL baseline & $-0.5(0.7)$ & $-0.7,-0.3$ & $+0.1(1.1)$ & $-0.1,+0.2$ & $-0.4(0.7)$ & $-0.7,0.0$ & $0.0(1.0)$ & $-0.3,+0.3$ \\
\hline \multicolumn{9}{|l|}{ MADRS total score } \\
\hline Change from DB baseline & $-6.9(6.7)$ & $-8.8,-5.0$ & $-3.5(7.9)$ & $-4.7,-2.3$ & $-5.4(7.3)$ & $-9.3,-1.5$ & $-2.7(9.2)$ & $-5.2,-0.3$ \\
\hline Change from OL baseline & $-1.8(4.9)$ & $-3.1,-0.4$ & $+0.8(7.0)$ & $-0.2,+1.9$ & $+2.7(8.1)$ & $-1.6,+7.0$ & $+2.5(8.8)$ & $+0.2,+4.9$ \\
\hline
\end{tabular}

PANSS: Positive and Negative Symptom Scale; CGI-S: Clinical Global Impression scale-Severity; MADRS: Montgomery-Åsberg Depression Rating Scale; DB: double-blind; OL: open-label; Cl: confidence interval; SD: standard deviation.

remission in the group of patients who were responders at open-label baseline compared with nonresponders (Figure 4 ; log-rank chi square, $7.63 ; P<0.01$ ). Nonetheless, among nonresponders at open-label baseline, $41 \%$ met RSWG criteria for remission at Month 6 and $47 \%$ at Month 12 (OC analysis). Conversely, $4.0 \%$ of responders lost their response by 6 months, and $2.9 \%$ at 12 months, defined as falling below the $20 \%$ PANSS total score improvement threshold.

\section{Discussion}

We report here the results of an open-label study in which patients diagnosed with an acute exacerbation of schizophrenia who completed an initial 6 week, doubleblind, placebo-controlled, fixed-dose trial of lurasidone received 22 months of continuation treatment with flexible doses of lurasidone, $40-120 \mathrm{mg} /$ day. The combined study treatment of up to 24 months represents the longest exposure to lurasidone in a controlled clinical trial that has been reported to date. Of the 251 patients who entered this extension study, $27 \%$ completed 22 months of extension treatment. The observed rate of attrition at endpoint (73\%) is consistent with results from other studies of oral antipsychotics with durations $\geq 18$ months. ${ }^{27,28}$ Withdrawal of consent $(24 \%)$ was the most common reason cited for early discontinuation, with adverse effects leading to treatment discontinuation cited in $\mathbf{1 4 . 8 \%}$ of patients.

The group of patients who continued into the current continuation study had shown marked improvement during the initial 6-week double-blind phase, as

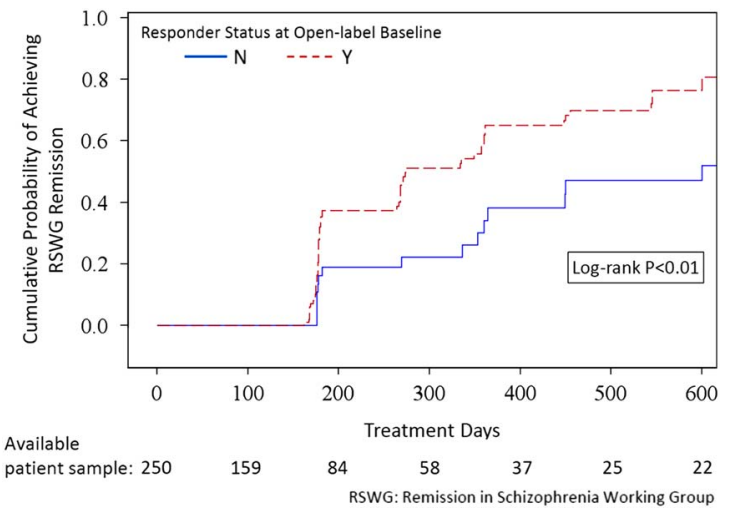

FIGURE 4. Kaplan-Meier estimate of the probability of achieving full RSWG remission during 22 months of extension phase treatment: results by responder status at open-label baseline.

demonstrated by a mean decrease in PANSS total score from 96.5 to 69.5 . The magnitude of acute improvement was very similar regardless of initial double-blind treatment assignment, likely reflecting a favorable selection bias in the placebo group (i.e., completers who improved sufficiently that they were willing to consider entering an extension study). Sustained response was observed in the majority of patients during 22 months of additional lurasidone treatment. A small number of responders at extension study baseline reported loss of response at Months 6 and 12 (4.0\% and $2.9 \%$, respectively). These results were consistent with other studies that have formally evaluated relapse prevention efficacy associated with lurasidone. ${ }^{19,29}$ 
In the current study, a high proportion of patients met full RSWG criteria for remission who completed 6 months $(62 \%)$ and 12 months $(67 \%)$ of treatment with lurasidone. RSWG criteria are rigorous and require 6 months of sustained symptomatic remission. ${ }^{20}$ These remission rates are very similar to the $61.9 \%$ remission rates reported after 12 months of treatment with lurasidone in the relapse prevention trial cited above. ${ }^{19}$ In an LOCF analysis, with dropouts included, RSWG remission rates in the current study were $28 \%$ at 12 months. By comparison, in the CATIE study, ${ }^{30}$ RSWG remission criteria were met by $11.7 \%$ of patients at 18 months. The higher remission rates in the current study are likely attributable to the shorter observation period (12 vs 18 months), but may also be due to differences in study populations, as well as differences in antipsychotic treatment regimens (including medication switching).

In up to 24 months of extension-phase treatment, lurasidone was generally well-tolerated, with the majority of adverse events in the mild-to-moderate severity range. Importantly, long-term treatment with lurasidone was associated with a low potential for adverse effects on weight, lipids, and glycemic indices. These results confirm and extend the findings of multiple shortterm $^{9-13}$ and two 1-year studies, ${ }^{17,19}$ and are consistent with the safety and tolerability data summarized in the U.S. product label. ${ }^{14}$

High rates of metabolic syndrome have been observed in schizophrenia, ranging up to $50 \%$ in some large samples, ${ }^{6,27}$ with a significant excess in cardiovascular mortality risk. ${ }^{31-33}$ There is growing concern that the cardiovascular mortality risk may be undergoing an iatrogenic increase since the introduction of secondgeneration antipsychotics. ${ }^{7,33-35}$ The current long-term data provide considerable evidence that treatment with lurasidone is associated with a low potential for adverse effects on weight and metabolic parameters. In light of comparative meta-analyses,${ }^{1}$ cardiometabolic safety has been established as an important consideration when choosing an antipsychotic. $1,3,36$

Consistent with previous studies, ${ }^{17}$ treatment with lurasidone was associated with minimal changes in prolactin levels, though there was a high degree of variability in prolactin levels, with a treatment-emergent shift from normal-to-high prolactin levels occurring in $7.2 \%$ of males and $12.5 \%$ of females. Lurasidone appears to have a modest effect on prolactin that is intermediate between aripiprazole and risperidone. ${ }^{1,37}$ The incidence of akathisia was $10.8 \%$, similar to rates reported in previous 12-month trials. ${ }^{13,17}$ Approximately 1 out of 5 patients treated with lurasidone received anticholinergic medication. As expected, patients treated initially with placebo and switched to lurasidone for the first time reported more frequent use of anticholinergic medication. Change in movement disorder signs or symptoms as measured by change in SAS, BARS, and AIMS scores was generally absent or mild.

The major limitation of the current study was the absence of a randomized, double-blind, active comparator to provide a benchmark for concurrent evaluation of both efficacy and safety outcomes. A second limitation, common to studies with durations of this length, is the high attrition rate, which should be taken into consideration while interpreting results of this study.

\section{Conclusions}

In this open-label extension study, the majority of patients demonstrated sustained improvement in the PANSS total score during up to 24 months of treatment with flexible doses of lurasidone in the range of 40-120 mg, administered once-daily. Rates for loss of response were low, and approximately two-thirds of patients completing 12 months of treatment met stringent remission criteria. Long-term treatment with lurasidone was associated with a low potential for adverse effects on weight, lipids, and glycemic indices. Taken together with findings from previous studies, lurasidone appears to be a safe and effective option for the long-term treatment of schizophrenia.

\section{Disclosures}

Christoph Correll has the following disclosures: AbbVie, consultant/advisor, honoraria; Bristol-Myers Squibb, researcher, research grant; Genetech, consultant/advisor, honoraria; Intra-Cellular Therapies, consultant/advisor, honoraria; Janssen Pharmaceuticals, consultant/advisor, honoraria; Actavis, consultant/ advisor, honoraria; Lundbeck Pharmaceuticals, consultant/advisor, honoraria; MEDACorp, consultant/ advisor, honoraria; Reviva, consultant/advisor, honoraria; Otsuka America Pharmaceuticals, researcher, research grant; Otsuka America Pharmaceuticals, consultant/advisor, honoraria; Pfizer, consultant advisor, honoraria; Roche Pharmaceuticals, consultant advisor, honoraria; Sunovion Pharmaceuticals, consultant advisor, honoraria; Takeda Pharmaceuticals, consultant advisor, honoraria; Gerson Lehrman Group, consultant advisor, honoraria; Medscape, consultant advisor, honoraria; ProPhase, consultant advisor, honoraria. Josephine Cucchiaro has the following disclosure: Sunovion, employee, salary. Robert Silva has the following disclosure: Sunovion, employee, salary. Jay Hsu has the following disclosure: Sunovion, employee, salary. Andrei Pikalov has the following disclosure: Sunovion, employee, salary. Antony Loebel has the following disclosure: Sunovion, employee, salary. 


\section{REFERENCES:}

1. Leucht S, Cipriani A, Spineli L, et al. Comparative efficacy and tolerability of 15 antipsychotic drugs in schizophrenia: a multiple-treatments meta-analysis. Lancet. 2013; $\mathbf{3 8 2}(9896)$ : 951-962.

2. Barnes TR, Schizophrenia Consensus Group of British Association for Psychopharmacology. Evidence-based guidelines for the pharmacological treatment of schizophrenia: Recommendations from the British Association for Psychopharmacology. J Psychopharmacol. 2011; 25(5): 567-620.

3. Glick ID, Correll CU, Altamura CA, et al. Mid-term and long-term efficacy and effectiveness of antipsychotic medications for schizophrenia: a data-driven, personalized, clinical approach. J Clin Psychiatry. 2011; 72(12): 1616-1627.

4. Correll CU, Lencz T, Malhotra AK. Antipsychotic drugs and obesity. Trends Mol Med. 2011; 17(2): 97-107.

5. De Hert M, Detraux J, van Winkel R, Yu W, Correll CU. Metabolic and cardiovascular adverse effects associated with antipsychotic drugs. Nat Rev Endocrinol. 2011; 8(2): 114-126.

6. Mitchell AJ, Vancampfort D, Sweers K, van Winkel R, Yu W, De Hert M. Prevalence of metabolic syndrome and metabolic abnormalities in schizophrenia and related disorders-a systematic review and meta-analysis. Schizophr Bull. 2013; 39(2): 306-318.

7. Correll CU, Joffe BI, Rosen LM, Sullivan TB, Joffe RT. Cardiovascular and cerebrovascular risk factors and events associated with secondgeneration antipsychotic compared to antidepressant use in a nonelderly adult sample: results from a claims-based inception cohort study. World Psychiatry. 2015; 14(1): 56-63.

8. Ishibashi T, Horisawa T, Tokuda K, et al. Pharmacological profile of lurasidone, a novel antipsychotic agent with potent 5-hydroxytryptamine 7 (5-HT7) and 5-HT1A receptor activity. J Pharmacol Exp Ther. 2010; 334(1): 171-181.

9. Nakamura M, Ogasa M, Guarino J, et al. Lurasidone in the treatment of acute schizophrenia: a double-blind, placebo-controlled trial. J Clin Psychiatry. 2009; 70(6): 829-836.

10. Meltzer HY, Cucchiaro J, Silva R, et al. Lurasidone in the treatment of schizophrenia: a randomized, double-blind, placebo and olanzapine-controlled study. Am J Psychiatry. 2011; 168(9): 957-967.

11. Citrome L. Lurasidone for schizophrenia: a review of the efficacy and safety profile for this newly approved second-generation antipsychotic. Int J Clin Pract. 2011; 65(2): 189-210.

12. Ogasa M, Kimura T, Nakamura M, Guarino J. Lurasidone in the treatment of schizophrenia: a 6-week, placebo-controlled study. Psychopharmacology (Berl). 2013; 225(3): 519-530.

13. Loebel A, Cucchiaro J, Sarma K, et al. Efficacy and safety of lurasidone $80 \mathrm{mg} /$ day and $160 \mathrm{mg} /$ day in the treatment of schizophrenia: a randomized, double-blind, placebo- and activecontrolled trial. Schizophr Res. 2013; 145(1-3): 101-109.

14. Sunovion Pharmaceuticals. Latuda (lurasidone HCl tablets). Prescribing Information. http://www.latuda.com/ LatudaPrescribingInformation.pdf. Accessed March 4, 2015.

15. Sunovion Pharmaceuticals. Lurasidone Summary of Product Characteristics. March 21 2014. http://www.ema.europa.eu/docs/ en_GB/document_library/EPAR___Product_Information/human/ 002713/WC500164683.pdf. Accessed February 15, 2016.

16. De Hert M, Yu WP, Detraux J, van Winkel R, Correll CU. Body weight and metabolic adverse effects of asenapine, iloperidone, lurasidone, and paliperidone in the treatment of schizophrenia and bipolar disorder: a systematic review and exploratory meta-analysis. CNS Drugs. 2012; 26(9): 733-759.

17. Citrome L, Cucchiaro J, Sarma K, et al. Long-term safety and tolerability of lurasidone in schizophrenia: a 12-month, double-blind, active-controlled study. Int Clin Psychopharmacol. 2012; 27(3): 165-176.

18. Stahl SM, Cucchiaro J, Simonelli D, Hsu J, Pikalov A, Loebel A. Effectiveness of lurasidone for patients with schizophrenia following 6 weeks of acute treatment with lurasidone, olanzapine, or placebo: a 6-month, open-label, extension study. J Clin Psychiatry. 2013; 74(5): 507-515.

19. Loebel A, Cucchiaro J, Xu J, Sarma K, Pikalov A, Kane JM. Effectiveness of lurasidone vs. quetiapine XR for relapse prevention in schizophrenia: a 12-month, double-blind, noninferiority study. Schizophr Res. 2013; 147(1): 95-102.

20. Andreasen NC, Carpenter WT Jr, Kane JM, Lasser RA, Marder SR, Weinberger DR. Remission in schizophrenia: proposed criteria and rationale for consensus. Am J Psychiatry. 2005; 162(3): 441-449.

21. Nasrallah HA, Silva R, Phillips D, et al. Lurasidone for the treatment of acutely psychotic patients with schizophrenia: a 6-week, randomized, placebo-controlled study. J Psychiatr Res. 2013; 47(5) 670-677.

22. Simpson GM, Angus JWS. A rating scale for extrapyramidal side effects. Acta Psychiatr Scand Suppl. 1970; 212: 11-19.

23. Barnes TRE. A rating scale for drug-induced akathisia. $\mathrm{Br} \mathrm{J}$ Psychiatry. 1989; 154(5): 672-676.

24. Guy W, ed. CDEU Assessment Manual for Psychopharmacology Publication ADM 76-338 Washington, DC: US Department of Health, Education, and Welfare; 1976: 534-537.

25. Kay SR, Fiszbein A, Opler LA. The positive and negative syndrome scale (PANSS) for schizophrenia. Schizophr Bull. 1987; 13(2): 261-276.

26. Montgomery SA, Åsberg M. A new depression scale designed to be sensitive to change. Br J Psychiatry. 1979; 134(4): 382-389.

27. Lieberman JA, Stroup TS, McEvoy JP, et al. Effectiveness of antipsychotic drugs in patients with chronic schizophrenia. $N$ Engl J Med. 2005; 353(12): 1209-1223.

28. Buckley PF. Maintenance treatment for schizophrenia with quetiapine. Hum Psychopharmacol. 2004; 19(2): 121-124.

29. Citrome L, Cucchiaro J, Sarma K, Phillips D, Silva R, Tsuchiya S, Loebel A. Long-term safety and tolerability of lurasidone in schizophrenia: a 12-month, double-blind, active-controlled study. Int Clin Psychopharmacol. 2012; 27(3): 165-176.

30. Levine SZ, Rabinowitz J, Ascher-Svanum H, Faries DE, Lawson AH. Extent of attaining and maintaining symptom remission by antipsychotic medication in the treatment of chronic schizophrenia: evidence from the CATIE study. Schizophr Res. 2011; 133(1-3): 42-46.

31. Ösby U, Correia N, Brandt L, Ekbom A, Sparén P. Time trends in schizophrenia mortality in Stockholm county, Sweden: cohort study. BMJ. 2000; 321(7259): 483-484.

32. Hennekens CH, Hennekens AR, Hollar D, Casey DE. Schizophrenia and increased risks of cardiovascular disease. Am Heart J. 2005; 150(6): 1115-1121

33. Saha S, Chant D, McGrath J. A systematic review of mortality in schizophrenia. Is the differential mortality gap worsening over time? Arch Gen Psychiatry. 2007; 64(10): 1123-1131.

34. Brown S, Kim M, Mitchell C, Inskip H. Twenty-five year mortality of a community cohort with schizophrenia. Br J Psychiatry. 2010; 196(2): 116-121.

35. Weinmann S, Read J, Aderhold V. Influence of antipsychotics on mortality in schizophrenia: systematic review. Schizophr Res. 2009; 113(1): 1-11

36. Meyer JM. Antipsychotics and metabolics in the post-CATIE era. Curr Top Behav Neurosci. 2010; 4: 23-42.

37. Inder WJ, Castle D. Antipsychotic-induced hyperprolactinaemia. Aust N Z J Psychiatry. 2011; 45(10): 830-837. 